Irina Yugfeld [Ирина Югфельд]

ORCID: 0000-0002-7784-1751

Московский городской педагогический университет

Институт педагогики и психологии образования

Москва, Россия

\title{
ПОДГОТОВКА БАКАЛАВРОВ К СОПРОВОЖДЕНИЮ ОДАРЕННЫХ ДЕТЕЙ В СИТУАЦИИ ИНКЛЮЗИИ
}

\author{
Preparing bachelor students for working \\ with gifted children in a situation of inclusion
}

https://doi.org/10.34739/sn.2020.20.07

\begin{abstract}
Аннотация: В статье анализируются возможности подготовки будущих педагогов к сопровождению одаренных школьников в инклюзивном образовании. Модернизировано содержание психолого-педагогических дисциплин, а также заданий по практике (исследовательские, диагностические, проектные). Разработана и реализована дисциплина по выбору «Психологопедагогические основы сопровождения одаренных школьников». Полученный бакалаврами субъективный опыт способствует формированию ценностного отношения к проблеме одаренного ребенка в контексте инклюзии.
\end{abstract}

Ключевые слова: одаренность, бакалавры, подготовка, теории одаренности, инклюзия, сопровождение, дети с особыми образовательными потребностями, школьное насилие, производственная практика.

Abstract: The article analyzes the possibilities of preparing future teachers to accompany gifted students in inclusive education. The content of psychological and pedagogical disciplines, as well as practical tasks (research, diagnostic, project) has been modernized. The discipline of choice "Psychological and pedagogical foundations of support for gifted students" developed and implemented. The subjective experience received by bachelors contributes to the formation of an attitude to the problem of a gifted child in the context of inclusion.

Keywords: giftedness, bachelors, training, theories of giftedness, inclusion, accompaniment, children with special educational needs, school violence, work experience 
Рассматривая одаренного ребенка как важнейший интеллектуальный ресурс современного социума, исследователи констатируют массовую неготовность педагогов работать с этой категорией школьников. Особые трудности наблюдаются при взаимодействии учителя с одаренным ребенком в инклюзивном образовании. Одаренный ребенок относится к группе риска и требует от учителя особенно внимательного и бережного отношения, Неслучайно эти дети зачастую оказываются жертвами школьного насилия. Адресная подготовка в университете будущих педагогов к сопровождению одаренного ребенка в инклюзивной среде - это один их наиболее действенных и перспективных путей приближения к решению данной проблемы. Для реализации этой цели в курсах педагогической, возрастной, социальной психологии, теоретической и практической педагогики были акцентированы вопросы, связанные с диагностикой учащихся, понятием одаренности, ее видов и уровней, с инклюзией. Бакалавры образования должны представлять особенности одаренных детей, знать индикаторы школьного насилия, способы преобразования деструктивных конфликтов в конструктивные. Дополнительно, в содержание этих дисциплин был включен материал, знакомящий студентов с практическим опытом успешного сопровождения педагогами одаренных детей в инклюзивном образовании [Ûgfel'd, 2016].

Понимая социальную и практическую значимость проблемы одаренного ребенка, особенно в ситуации инклюзивного образования, мы разработали и реализовали в образовательном процессе дисциплину по выбору «Психолого-педагогические основы сопровождения одаренного ребенка в инклюзивном образовании». Содержание курса включало характеристику подходов отечественных и зарубежных исследователей к пониманию сущности, структуры одаренности, теории и концепции одаренности в историческом и современном контексте. Виды, критерии, признаки одаренности, личностные особенности ребенка - вся эта информация необходима учителю для обоснованного и грамотного поведения в реальной практической ситуации [Larionova, Sokolova, 2019]. 
Одаренность традиционно рассматривается как повышенный уровень развития одной или нескольких способностей человека, позволяющий ему достигать высоких успехов в социально значимых видах деятельности, что выделяет его среди других представителей данной возрастной или социальной группы. Одаренность представляет собой системное качество, сложную взаимосвязь и взаимозависимость познавательной, эмоциональной, волевой, личностной сфер психики. Одаренный ребенок выделяется очевидными достижениями в каком-либо виде деятельности или имеет внутренние предпосылки для подобных достижений. Бакалаврам образования важно понимать, что наряду с явной одаренностью существует латентная, то есть, одаренность, которая по каким-то причинам не проявила себя в учебной или иной деятельности ребенка. Будущие педагоги обсуждали категориальное пространство проблемы одаренности (понятия «способности», "талант», «гениальность»), позитивные и негативные особенности одаренных школьников, индикаторы психологически безопасной образовательной среды. Учителя ценят такие качества одаренных учащихся как выраженный познавательный интерес, поисковая активность, любознательность, самостоятельность и инициативность в учебном процессе. Эти школьники имеют значительный объем знаний, высокий уровень интеллекта, отличную память, большой словарный запас, логичную речь, используют сложные синтаксические конструкции. Вместе с тем, эту категорию детей нередко отличает эмоциональная неуравновешенность, перепады настроения, невротизм, повышенное чувство справедливости, чрезмерно высокие требования к себе и окружающим. Выраженный нонконформизм, низкая стрессоустойчивость, импульсивность, перфекционизм, критичность - эти качества делают одаренных детей более беззащитными и уязвимыми. Для учащихся этой группы характерна высокая чувствительность, они обращают особое внимание на интонации, жесты, позы, мимику учителя, родителей, своих одноклассников. Особые качества одаренного ребенка связаны также со спецификой его дизонтогенеза, с конкретными физическими или психическими проблемами [Larionova, 2018]. 
Процесс адаптации одаренного ребенка в социуме может протекать длительно и сложно, возможны нервно-психические срывы. Нетерпимость, конфликтность, гипертрофированные страхи и опасности, готовность исправлять ошибки других (и одноклассников, и учителя) могут привести к изоляции одаренного ребенка в классе, к формированию негативной Я-концепции, снижению самооценки, использованию неадекватных механизмов психологической защиты. В образовательном пространстве школы, по данным статистики, каждый четвертый ребенок подвергается травле. Моббинг со стороны педагога проявляется в частой и необоснованной критике одаренного ребенка, в несправедливых замечаниях, в сарказме, иронии, прямых оскорблениях. Моббинг учителя может восприниматься школьникам как образец для подражания, как «руководство к действию». Буллинг как запугивание, регулярный физический или психологический террор в отношении ребенка, осуществляемый одним или несколькими одноклассниками [Larionova, Sokolova, 2019].

Бакалавры образования рассмотрели теорию одаренности с позиции реализации творческого потенциала человека (А.М. Матюшкин и В.С. Юркевич). Одаренность - высокий уровень творческого потенциала, исследовательская активность личности. Особую значимость в контексте данного подхода приобретает ранняя диагностика детей, использование адресных дидактических методов и технологий, стимулирующих познавательную потребность и творческую активность ребенка. Студенты познакомились также с динамической теорией одаренности (Ю.Д. Бабаева). Для будущих учителей важно не только оценивать уровень развития способностей, но и находить те препятствия, которые мешают развитию одаренного ребенка при наличии у него физических или психических ограничений. Возникшие преграды должны рассматриваться как «целевые точки» психического развития ребенка, стимулирующие включение компенсаторных процессов.

В целях формирования у будущих учителей ценностносмыслового отношения к проблеме одаренного ребенка были внесены коррективы в содержание психолого-педагогических 
дисциплин, технологии их изучения. В семинарские занятия включались кейс-технологии, ориентированные на самостоятельную работу студентов. Контент кейсов позволял осуществить диагностику, анализ и интерпретацию результатов, предложить рекомендации для учителей и родителей [Ûgfel'd, 2016].

Для формирования у студентов эмоционально-ценностного отношения к проблеме одаренности были модернизированы задания производственной практики. Бакалаврам образования предлагалось в ходе беседы с учителями и школьными психологами выяснить их отношение к одаренным детям, уточнить, как осуществляется сопровождение, какие сложности возникают во взаимодействии с детьми с особыми образовательными потребностями. Значительное число опрошенных учителей на основе повседневного наблюдения считает, что в их классах нет одаренных школьников. Даже при наличии в центре образования психологической службы от педагогов не было запросов о психодиагностике (в частности, об использовании методики Дж. Рензулли «Поведенческие характеристики одаренных»). Педагогическое сопровождение одаренных школьников в реальной образовательной ситуации сводится к более объемным и сложным заданиям [Larionova, 2018].

Процесс сопровождения одаренных детей с особыми образовательными потребностями в учебной деятельности предполагает создание учителем ситуаций выбора, побуждение ребенка к самостоятельному нахождению решений и принятию на себя ответственности [Levterova-Gadžalova, 2019].

B процессе проведения уроков по своему предмету студенты создавали ситуации выбора, предлагая ученикам самим выбрать домашнее задание из нескольких вариантов, используя исследовательские, проектные, междисциплинарные задания. Мы надеемся, что полученный в квази-профессиональной деятельности собственный опыт будет в будущем перенесен выпускниками в реальную образовательную практику. Студенты убедились, что сопровождение учителем одаренных школьников предполагает создание ситуаций выбора на основе учета специфики их 
дизонтогенеза, использование проектных, диалоговых, игровых, компьютерных технологий, а также тесное сотрудничество с психологами, коллегами, родителями детей.

\section{Literature [Литература]}

Larionova L., Sokolova O. (2019), Social'nye predstavleniâ studentov ob odarennyh detâh, [v:] E. Rangelova (ed.), Vzaimodejstvie na prepodavatelâ i studenta, vusloviâta na universitetskoto obrazovanie: teorii, tehnologii, upravlenie, Eks-Pres, Gabrovo, s. 186-188.

Larionova M.A. (2018), Professional'noe razvitie pedagoga pri organizaciipsihologo-pedagogičeskogo soprovoždeniâ odarennogo škol'nika, [v:] L. Mitina (ed.), Ličnostno-professional'noe i kar'ernoe razvitie: aktual'nye issledovaniâ iforsajt-proekty, Izdatel'stvo "Pero", Moskva, s. 123-127.

Levterova-Gadžalova D. (2019), Profesionalnata podgotovka na resursniâ učitel-najznačimiât poslanik na priobŝavaŝoto obrazowanie, [v:] E. Rangelova (ed.), Vzaimodejstvie na prepodavatelâ i studenta, vusloviâta na universitetskoto obrazovanie: teorii, tehnologii, upravlenie, Eks-Pres, Gabrovo, s. 171-177.

Ûgfel'd I.A. (2016), Psihologičeskaâ bezopasnost' obrazovatel'noj sredy v aspekte igrovogo modelirovaniâ, [v:] E. Rangelova (ed.), Teoriâ i praktika na psihologo-pedagogičeskata podgotovka na specialista $v$ universiteta. Vtora kniga, Eks-Pres, Gabrovo, s. 410-413. 